\title{
The impact of pulmonary rehabilitation on severe physical inactivity in patients with chronic obstructive pulmonary disease: a pilot study
}

This article was published in the following Dove Press journal: International Journal of COPD

\author{
Mimi Thyregod ${ }^{1,2}$ \\ Anders Løkke 3 \\ Uffe Bodtger ${ }^{1,2}$
}

'Department of Respiratory Medicine, Naestved Hospital, Naestved, Denmark; ${ }^{2}$ Institute for Regional Health Research, University of Southern Denmark, Odense, Denmark; ${ }^{3}$ Department of Respiratory Diseases and Allergy, Aarhus University Hospital, Aarhus, Denmark

Correspondence: Mimi Thyregod Department of Respiratory Medicine, Naestved Hospital, Ringstedgade 6I, Naestved 4700, Denmark

Tel +452982 8I 97

Email mimithyregod@gmail.com
Introduction: In patients with COPD, severe physical inactivity (SPI, which is defined as total daily energy expenditure/resting energy expenditure; physical activity level [PAL] ratio, <1.4) is associated with increased morbidity and mortality. Pulmonary rehabilitation (PR) increases physical capacity in COPD, but the impact on SPI is unknown. In this study, we aimed at elucidating the prevalence of SPI in COPD patients attending standard PR, the impact of PR on SPI prevalence, and the relationship between SPI and time spent in moderate physical activity thus whether American College of Sports Medicine (ACSM) recommendations are clinically useful in excluding SPI in COPD.

Methods: This is a prospective non-interventional pilot study on patients with COPD completing PR, consenting to wear an accelerometer (Sensewear ${ }^{\odot}$ Armband) for a week before and after completing PR to assess changes in energy expenditure, time spent in physical activity, and number of daily steps. Low level of daily physical activity was not an inclusion criterion.

Results: In total, 57 patients completed the study and 31 (54\%) had SPI at baseline. In patients with SPI, baseline median $\mathrm{FEV}_{1}$ was 48 (range, 28-86) \% of predicted and GOLD B, n=11 (35\%)/GOLD D, $\mathrm{n}=20$ (65\%). Surprisingly, 31 of SPI patients (97\%) spent $\geq 150$ minutes/week in moderate physical activity. After rehabilitation, 24 (78\%) did not change activity level and were persistently SPI. We observed no differences at baseline between patient responding $(n=7)$ vs not responding $(n=24)$ to PR. Responders increased number of daily steps and time spent in lighter but not moderate physical activity during rehabilitation.

Conclusion: In this pilot study, SPI was prevalent, and PR had limited impact. Contraintuitively, most patients with SPI complied with general recommendations of weekly hours spent in moderate physical activity. Our study highlights that increasing time spent in light activity rather than improving time spent in moderate activity is important in COPD patients with chronic dyspnea.

Keywords: COPD, pulmonary rehabilitation, severe physical inactivity, Sensewear ${ }^{\odot}$

\section{Introduction}

COPD is associated with reduced levels of daily physical activity. ${ }^{1}$ The chronic airflow limitation results in exercise-limiting dyspnea and fatigue, and in particular, COPD patients are at risk for severe physical inactivity (SPI), which is defined as a total daily energy expenditure/resting energy expenditure ratio $<1.4 .^{2-4} \mathrm{SPI}$ is prevalent in the majority of COPD patients in GOLD group $\mathrm{D}^{5}$ and is highly related to both morbidity and mortality. ${ }^{6-8}$ However, SPI assessment requires measurement of resting energy expenditure by indirect calorimetry or an accelerometer (eg, SenseWear ${ }^{\odot}$ Armband; BodyMedia, Pittsburgh, PA, USA) because no equation for calculated resting energy 
expenditure has shown acceptable accuracy in COPD. ${ }^{9}$ According to the American College of Sports Medicine (ACSM), healthy subjects are recommended to engage in moderate physical activity for 30 minutes a day - at least 5 days a week - to reduce the risk of chronic diseases and disabilities. ${ }^{10}$ The same recommendations are applicable for older adults according to WHO. ${ }^{11}$ In COPD, it is not known whether complying with the ACSM goal precludes SPI.

Pulmonary rehabilitation (PR) is a validated intervention in COPD, and exercise is the cornerstone of the program. ${ }^{12}$ Even though high intensity and duration of physical activity are negatively correlated to morbidity and mortality in COPD, ${ }^{2,5,6,13-15}$ it is not known whether the standard ACSM recommendation is a relevant success criterion for $\mathrm{PR}$ in COPD. ${ }^{6,76-19}$ Recent research has suggested that lighter activities are more efficient in avoiding inactivity including SPI than heavier physical activities. ${ }^{3,4,15,20,21}$

In the present study, we aimed at elucidating the prevalence of SPI in COPD patients attending standard PR, the impact of PR on the prevalence of SPI, and the relationship between SPI and time spent in moderate physical activity, thus it is unknown if the ASCM recommendations is clinically useful in excluding SPI in COPD.

\section{Methods}

\section{Design}

This prospective, observational cohort study was designed as a pilot study and conducted in 2013-2014 in PR centers at Naestved Hospital and in the communities of Naestved, Faxe, and Vordingborg centers (Region Zealand, Denmark). Patients were enrolled on the first day of the rehabilitation program (Visit 1) and had a follow-up visit in the last week of the rehabilitation course (Visit 2).

\section{Inclusion criteria}

Inclusion criteria were physician-diagnosed COPD confirmed by spirometry (GOLD classes B-D), ${ }^{12}$ referral for PR, ability to give informed consent, no other life-threatening illnesses, no history of asthma, and no acute exacerbation within the last 4 weeks prior to inclusion. ${ }^{22}$

Written and oral informed consent was obtained. This study was approved by the Danish National Ethical Committee and complied with the Declaration of Helsinki. The study is registered with ClinicalTrials.gov (number 34431).

\section{Study procedures}

The rehabilitation program consisted of exercise training, education in management of disease and pharmacology, nutrition, and help with smoking cessation. The duration of the program ranged from 7 to 12 weeks, 2 hours twice a week according to the guidelines from the Danish Health Authority. ${ }^{23}$ The exercise training consisted of 1 hour of supervised training twice a week with an equal distribution between endurance and resistance training. ${ }^{23}$ Spirometry (MicroLoop ${ }^{\odot}$ spirometer; Becton, Dickinson and Company, Franklin Lakes, NJ, USA) measurement was performed at both visits according to the guidelines of the American Thoracic Society (ATS) and the European Respiratory Society (ERS). ${ }^{24}$ Patient-reported outcome measures were obtained at both visits. Background data were obtained at Visit 1: gender, weight, height, and exacerbations (acute exacerbation in COPD [AECOPD]) comorbidities and medication.

\section{Primary and secondary outcomes}

Primary outcome

The primary outcome of this study was the prevalence of SPI before and after PR.

\section{Secondary outcomes}

The secondary outcome of this study was minutes spent in light respective moderate physical activity, number of patients spending $\geq 150$ minutes/week in light ( $\geq 2$ Metabolic Equivalent of Task [MET]) respective moderate ( $\geq 3$ MET) physical activity, number of daily steps, and patientreported outcome measures (COPD assessment test [CAT] and $\mathrm{mMRC}$ ) before and after PR.

\section{Physical activity assessment}

Subjects were instructed to wear an activity monitor (SenseWear Armband) continuously for 7 days after each study visit. The use of SenseWear in patients with COPD has previously been validated. ${ }^{29,30}$ According to the manufacturer's recommendation, the activity monitor is worn on the back of the upper right arm at the level of the triceps. This monitor assesses acceleration in two planes by using a bi-axial accelerometer which measures and stores skin temperature, near body temperature, heat flux and galvanic skin resistance. Activity is estimated in MET, a measure of energy expenditure ( $1 \mathrm{MET}=1 \mathrm{kcal} / \mathrm{kg} / \mathrm{h})$. Output from the SenseWear includes the following:

- Total energy expenditure (TEE): number of calories burnt every day.

- Resting metabolic rate (RMR): the rate at which the body burns energy when it is at complete rest.

- Physical activity level (PAL): TEE divided by the RMR. 
- Minutes spent at light ( $\geq 2$ MET) and moderate $(\geq 3$ MET) physical activity.

- Daily number of steps.

Data from patients wearing the monitor $>2$ days and $>90 \%$ of daily use were included. ${ }^{25}$

\section{Patient-reported outcome measures}

CAT consisted of a self-reported, well-validated 5-point Likert scale, eight-item questionnaire with four respiratory items and four general health items (score range, 0-40). ${ }^{26}$ mMRC scale consisted of a self-reported, well-validated, 5-point Likert scale, one-item questionnaire (score range, $0-4)$. A score $\geq 2$ is considered "severe dyspnea" and is an inclusion criterion for PR in Denmark. ${ }^{12,18}$

\section{Statistical analyses}

Statistical analyses were performed using STATA 14.1. Missing data were omitted from analyses.

Continuous data are presented as a median (range) and categorical data as incidence (\%). Differences were assessed using the chi-squared test or Wilcoxon signed-rank test. Statistical significance was set at $P<0.05$.

\section{Results}

\section{Patients}

Between January 15, 2013, and February 10, 2014, 163 patients were consecutively screened, and 67 patients were included
(Figure 1). Totally, 57 patients completed the trial (communitybased rehabilitation: $n=43,75 \%$; hospital-based rehabilitation: $\mathrm{n}=14,25 \%$ ) and were included in the analysis (female: $53 \%$; age, 68 years [range, 50-80 years]). Baseline median $\mathrm{FEV}_{1}$ was 50 (range, 22-96) \% of predicted, and patients were divided between GOLD class $B(n=28)$ respective $D(n=29)$. Median body mass index (BMI) was $27 \mathrm{~kg} / \mathrm{m}^{2}$ (range, 17-51 kg/m²), and median self-reported number of moderate to severe AECOPD in preceding 12 months was 1 (0-7; Table 1). Patients completing the study and patients dropping out did not differ significantly in baseline characteristics. Eight of the patients (14\%) had missing SenseWear data at either baseline or follow-up. Table 2 shows that $74 \%$ complied with the ASCM's recommendation for physical activity at baseline and that PR increased time spent in light but not moderate physical activity. Nine patients $(16 \%)$ used a walker, and they did not differ significantly regarding daily steps or minutes/week spent in $\geq 3$ MET as opposed to patients not using walking aids. We registered the following comorbidities: 1) ischemic heart disease, $\mathrm{n}=3(5 \%) ; 2)$ heart failure, $\mathrm{n}=12(21 \%) ; 3)$ osteoporosis, $\mathrm{n}=5$ $(9 \%) ; 4)$ arthritis or joint pain, $\mathrm{n}=32(56 \%) ; 5)$ anxiety, $\mathrm{n}=18$ $(32 \%) ; 6)$ depression, $\mathrm{n}=9(16 \%) ; 7)$ stroke or other neurologic disease, $n=5(9 \%)$; and 8$)$ diabetes, $n=4(7 \%)$.

\section{Patients with SPI at baseline}

Totally, 31 (54\%) patients had SPI at baseline, yet $96 \%$ of patients with baseline SPI spent $\geq 150$ minutes/week

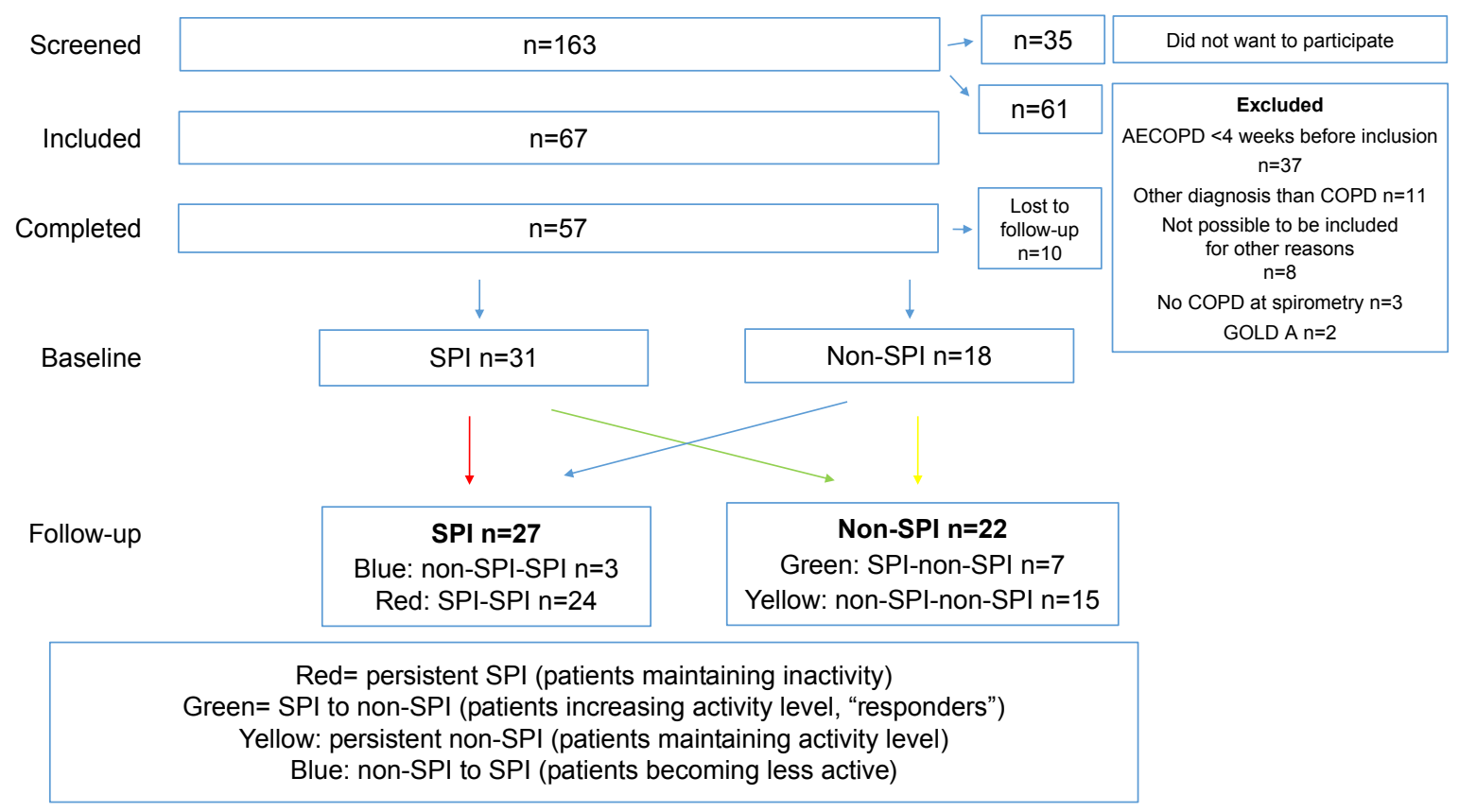

Figure I Flowchart of patients included in the study.

Abbreviation: AECOPD, acute exacerbation in COPD; SPI, severe physical inactivity. 
Table I Group characteristics $(n=57)$

\begin{tabular}{|l|l|}
\hline & Visit I \\
\hline Age (years), median (range) & $68(50-80)$ \\
\hline Female gender, $n(\%)$ & $30(53)$ \\
\hline BMI, median (range) & $27(17-5 \mathrm{I})$ \\
\hline FEV, (\% predicted), median (range) & $50(22-96)$ \\
\hline GOLD, n (\%) & \\
\hline A & $0(0)$ \\
\hline B & $28(49)$ \\
\hline C & $0(0)$ \\
\hline D & $29(5 \mathrm{I})$ \\
\hline Community/hospital, n (\%) & $43(75) / / 4(25)$ \\
\hline CAT, median (range) & $17(4-32)$ \\
\hline mMRC, median (range) & $2(1-4)$ \\
\hline AECOPD in the recent year, median (range) & $\mathrm{I}(0-7)$ \\
\hline
\end{tabular}

Abbreviations: AECOPD, acute exacerbation in COPD; BMI, body mass index; CAT, COPD Assessment Test.

in moderate physical activity ( $\geq 3$ MET), thus complying with ASCM recommendation for the general population (Table 2). Only seven patients (22\%) responded to PR by increasing PAL to $\geq 1.4$ ("responders"; Table 2). Responders significantly improved number of daily steps and time spent in lighter but not moderate physical activity compared to patients with persistent SPI. Analyzing differences between responders and patients with persistent SPI revealed no significant baseline differences (Table 3 ).

\section{Discussion}

This pilot study showed that SPI is prevalent in patients referred for PR and that rehabilitation improved objectively measured physical activity in a minority of these patients. To our knowledge, this is the first study to address these issues.

It is well established that self-reported level of physical activity is poorly associated with objectively measured physical activity. ${ }^{27}$ Surprisingly, we found that $96 \%$ of patients with SPI spent $\geq 150$ minutes/week in objectively measured moderate physical activity. Thus, the general recommendations for physical activity by $\mathrm{ACSM}^{10}$ seem not to be clinically meaningful in COPD patients with chronic dyspnea (mMRC, $\geq 2$ ). Our data support that increasing lighter rather than moderate or hard physical activity is more efficient in reducing sedentary lifestyle. ${ }^{3,4,16,20,21}$ However, the paradoxical finding of sedentary lifestyle (SPI) and sufficient amounts of moderate physical activity might have other explanations. As SPI is defined as a low ratio between total daily energy expenditure and resting energy expenditure, SPI might be a result of low total daily energy expenditure and/or increased resting energy expenditure. Several studies have found that moderate to severe COPD is associated with increased resting energy expenditure, lower fat-free body mass, and increased protein turnover. ${ }^{4,5,28}$ In addition, more profound structural and metabolic changes in peripheral and respiratory muscles seen in COPD patients result in increased energy expenditure $(\mathrm{kcal} / \mathrm{kg} / \mathrm{h}=\mathrm{MET})$ at lower levels of exercise. ${ }^{29}$ This is even more pronounced with low BMI, as energy expenditure is weight dependent; however, Kao et $\mathrm{al}^{28}$ found that low fat-free mass but not low BMI was associated with increased energy expenditure. We found no differences in baseline BMI in responders vs patients with persistent SPI (Table 2), but did not include measurements of fat-free mass. We found no differences in resting energy expenditure between responders and patients with persistent SPI, but the statistical power was low due to the limited sample size; thus, we cannot rule out that COPD patients with SPI benefiting from PR is a distinct subgroup.

The PAL and time spent in moderate physical activity are two different ways to measure physical activity, and both are important predictors of morbidity and mortality. ${ }^{6-8,10}$ Although the impact of PR on quality of life (QoL), exercise capacity, and dyspnea is well established, less evidence exists on the impact on time spent in moderate daily physical activity, although some studies have focused on daily steps and walking speed. ${ }^{22,30-37}$

Table 2 Impact of pulmonary rehabilitation on time spent in physical activity and number of patients being active for $\geq I 50$ minutes/ week measured using activity monitor (SenseWear ${ }^{\odot}$ ) during I week

\begin{tabular}{|l|l|l|l|l|}
\hline \multirow{2}{*}{} & \multicolumn{2}{l|}{ All participants $(\mathbf{n}=\mathbf{5 7})$} & \multicolumn{2}{l|}{ SPI at baseline $(\mathbf{n}=\mathbf{3 I})$} \\
\cline { 2 - 5 } & Baseline & Follow-up & Baseline & Follow-up \\
\hline Hours/week at $\geq 3.0$ MET (moderate physical activity), median (range) & $6.0(0-59)$ & $7.7(0.1-32)$ & $4.4(0.2-2 I)$ & $4.8(0.1-14)$ \\
\hline Patients with $\geq 3.0$ MET (moderate physical activity) in $\geq 150$ minutes/week, $n(\%)$ & $39(74)$ & $42(79)$ & $21(69)$ & $22(76)$ \\
\hline Hours/week at $\geq 2.0$ MET (light physical activity), median (range) & $18.8(0.8-6 I)$ & $21.5(1.9-59)^{\mathrm{a}}$ & $9.9(0.8-39)$ & $16.8(I .9-3 I)$ \\
\hline Patients with $\geq 2.0$ MET (light physical activity) in $\geq 150$ minutes/week, $n(\%)$ & $50(94)$ & $52(98)$ & $3 I(97)$ & $28(97)$ \\
\hline
\end{tabular}

Note: ${ }^{P}<0.05$, intragroup difference between time points.

Abbreviations: MET, Metabolic Equivalent of Task; SPI, severe physical inactivity. 
Table 3 Subgroup analyses of patients with SPI at baseline $(n=31)$ : differences at baseline and follow-up between patients remaining severely inactive (SPI) and patients not being severely inactive (non-SPI) at follow-up (responders)

\begin{tabular}{|c|c|c|c|c|}
\hline & \multicolumn{2}{|c|}{ Persistent SPI $(n=24)$} & \multicolumn{2}{|l|}{ Responders (n=7) } \\
\hline & Baseline & Follow-up & Baseline & Follow-up \\
\hline $\begin{array}{l}\text { Physical activity level (TEE divided by RMR), } \\
\text { median (range) }\end{array}$ & $1.3(1.2-1.3)$ & $1.3(1.1-1.3)^{\mathrm{a}}$ & $\mathrm{I} .3(\mathrm{I} . \mathrm{I}-\mathrm{I} .3)^{\mathrm{b}}$ & I.4 (I.4-I.5) \\
\hline Resting energy expenditure (J/day) & $6,552(4,464-9,768)$ & $6,969(4,344-8,784)$ & $6,432(4,872-9,768)$ & $7,032(4,728-10,920)$ \\
\hline Steps, median (range) & $\mathrm{I}, 758(226-5,50 \mathrm{I})$ & $1,683(180-5,065)^{a}$ & $3,149(112-4,755)$ & $4,015(1,598-5,564)^{\mathrm{a}}$ \\
\hline Minutes/week at $\geq 3 \mathrm{MET}$, median (range) & $264(12-1,098)$ & $276(6-810)$ & $348(48-1,284)$ & $546(\mid 38-1,704)$ \\
\hline $\begin{array}{l}\text { No of patients with } \geq 3 \text { MET in } 150 \text { minutes/week, } \\
n(\%)\end{array}$ & $15(60)$ & $18(75)$ & $5(7 I)$ & $6(86)$ \\
\hline Minutes/week in $\geq 2$ MET, median (range) & $552(48-2,160)$ & $960(114-1,860)^{\mathrm{a}}$ & I, $164(252-2,340)$ & $\mathrm{I}, 608(1,200-2,520)^{\mathrm{a}}$ \\
\hline $\begin{array}{l}\text { No of patients with } \geq 2 \text { MET in } 150 \text { minutes/week, } \\
n(\%)\end{array}$ & $22(92)$ & $23(96)$ & $7(100)$ & $7(100)$ \\
\hline CAT, median (range) & $17(10-32)$ & $16(7-29)$ & $17(11-28)$ & $19(11-34)$ \\
\hline mMRC, median (range) & $2(I-4)$ & $2(0-4)$ & $2(I-4)$ & $2(1-4)$ \\
\hline BMI, median (range) & $27.9(18.4-42.9)$ & & $27.0(16.6-27.8)$ & \\
\hline $\mathrm{FEV}_{1}$ (\% predicted), median (range) & $48(28-73)$ & & $54(26-96)$ & \\
\hline COPD class B, n (\%) & $9(38)$ & & $2(29)$ & \\
\hline
\end{tabular}

Notes: antergroup difference, $P<0.05$. 'Intragroup difference, $P<0.05$. Gray box, only baseline data available.

Abbreviations: BMI, body mass index; CAT, COPD Assessment Test; MET, Metabolic Equivalent of Task; RMR, resting metabolic rate; SPI, severe physical inactivity; TEE, total energy expenditure.

\section{Limitations}

There are several limitations in this study, which needs consideration. First, the present study is a pilot study and thus vastly underpowered to draw solid conclusion on statistically insignificant findings. However, this observational study included COPD patients admitted daily for PR and was not preselected according to self-reported or measured levels of physical activity. Second, PR was delivered at four sites with different duration despite involving mandatory elements of training and education twice a week according to the Danish guidelines. ${ }^{23}$ Our data sample was too small to adjust for this heterogeneity. Yet, the recommended duration of PR varies among guidelines (4-12 weeks American Association of Cardiovascular and PR; $\geq 8$ weeks ATS/ERS; not specified by ASCM), whereas these guidelines agree on sessions at least three times weekly. ${ }^{38}$ Thus, we might have observed a smaller impact of rehabilitation by following the Danish guidelines. It will be interesting to ascertain SPI prevalence as well as impact of rehabilitation in larger centers with more prevalent sessions.

Third, the accelerometer used (SenseWear) has - despite being well validated in $\mathrm{COPD}^{39}$ - several limitations. It is worn on the upper right arm and is not usable in water. Thus, measurements of energy expenditure during swimming or activities with fixed arms (eg, cycling, walking aids) are absent or underestimated. In our cohort, a minority used a walker. Furthermore, to ensure representative activity data, we excluded data if SenseWear was worn for $<48$ hours or if on-body time was $<90 \%$. In addition to the challenge of recollecting physical activity, Pitta et $\mathrm{al}^{40}$ reported adherence difficulties on using an accelerometer in 19\% of COPD subjects including body placement and technical issues, such as battery problems. In our study, the missing SenseWear data were $14 \%$ both due to exclusion criteria as mentioned above and complete lack of obtained data. Little is known about the day-to-day variations in objectively measured physical activity in moderate to severe COPD patients, but it is considerable in healthy adults. ${ }^{41}$ It has been documented that PALs increase during the week wearing an accelerometer, probably due to the novelty-induced increased awareness of healthy living. ${ }^{41,42}$ Fourth, we did not adjust for comorbidities such as osteoporosis, low back pain, diabetes, poor nutrition, cognitive dysfunction, heart disease, rheumatoid diseases, anxiety, or depression, which are all independently associated with decreased physical activity. ${ }^{38,40,43-46}$ Even though comorbidities are present in $70 \%$ of COPD patients and known to interfere with the outcome of PR, an improvement is still seen. ${ }^{47,48}$ However, the impact of exercise training provided during rehabilitation is not COPD specific, and all patients volunteered to participate in the rehabilitation program and the study. This selection probably selected the patients most eager to improve their levels of physical activity. 


\section{Conclusion}

Our present pilot study suggests that objectively measured SPI is common in patients referred for PR, which only improves daily physical activity in a minority of subjects despite wearing an accelerometer in a clinical trial. SPI at baseline was not precluded by being moderately physically active for $\geq 150$ minutes/week. As SPI is significantly associated with morbidity and mortality, future studies should address SPI-focused intervention strategies and elucidate factors associated with failure to improve physical activity in COPD patients receiving PR.

\section{Acknowledgments}

The study was supported by the Research Unit at Naestved Hospital and through a one-year scholarship from Southern University of Denmark. Financial contributions to equipment and laboratory testing were provided by Maersk Foundation, Meyers scholarship, and the local Research Foundation at Naestved Hospital.

\section{Disclosure}

The authors report no conflicts of interest in this work.

\section{References}

1. Van Remoortel H, Hornikx M, Demeyer H, et al. Daily physical activity in subjects with newly diagnosed COPD. Thorax. 2013;68(10): 962-963.

2. Cindy Ng LW, Mackney J, Jenkins S, Hill K. Does exercise training change physical activity in people with COPD? A systematic review and meta-analysis. Chron Respir Dis. 2012;9(1):17-26.

3. Manini TM, Everhart JE, Patel KV, et al. Daily activity energy expenditure and mortality among older adults. JAMA. 2006;296(2):171-179.

4. Watz H, Waschki B, Meyer T, Magnussen H. Physical activity in patients with COPD. Eur Respir J. 2009;33(2):262-272.

5. Watz H, Waschki B, Boehme C, Claussen M, Meyer T, Magnussen H. Extrapulmonary effects of chronic obstructive pulmonary disease on physical activity: a cross-sectional study. Am J Respir Crit Care Med. 2008; 177(7):743-751

6. Garcia-Aymerich J, Lange P, Benet M, Schnohr P, Antó JM. Regular physical activity reduces hospital admission and mortality in chronic obstructive pulmonary disease: a population based cohort study. Thorax. 2006;61(9):772-778.

7. Waschki B, Kirsten A, Holz O, et al. Physical activity is the strongest predictor of all-cause mortality in patients with COPD: a prospective cohort study. Chest. 2011;140(2):331-342.

8. Gimeno-Santos E, Frei A, Steurer-Stey C, et al. Determinants and outcomes of physical activity in patients with COPD: a systematic review. Thorax. 2014;69(8):731-739.

9. Rao ZY, Wu XT, Wang MY, Hu W. Comparison between measured and predicted resting energy expenditure in mechanically ventilated patients with COPD. Asia Pac J Clin Nutr. 2012;21(3):338-346.

10. Haskell WL, Lee IM, Pate RR, et al. Physical activity and public health: updated recommendation for adults from the American College of Sports Medicine and the American Heart Association. Med Sci Sports Exerc. 2007;39(8):1423-1434.
11. WHO [homepage on the Internet]. Physical Activity and Older Adults Recommended levels of physical activity for adults aged 65 and above; 2018. Available from: http://www.who.int/dietphysicalactivity/factsheet_olderadults/en/. Accessed September 26, 2018

12. GOLD. GOLD 2017 Global Strategy for the Diagnosis, Management, and Prevention of Chronic Obstructive Pulmonary Disease; 2017. Available from: https://goldcopd.org/gold-2017-global-strategydiagnosis-management-prevention-copd/. Accessed October 4, 2018.

13. Garcia-Aymerich J, Lange P, Benet M, Schnohr P, Antó JM. Regular physical activity modifies smoking-related lung function decline and reduces risk of chronic obstructive pulmonary disease: a population-based cohort study. Am J Respir Crit Care Med. 2007;175(5):458-463.

14. Kanda M, Minakata Y, Matsunaga K, et al. Validation of the triaxial accelerometer for the evaluation of physical activity in Japanese patients with COPD. Intern Med. 2012;51(4):369-375.

15. Bahadori K, Fitzgerald JM. Risk factors of hospitalization and readmission of patients with COPD exacerbation - systematic review. Int J Chron Obstruct Pulmon Dis. 2007;2(3):241-251.

16. Pitta F, Troosters T, Spruit MA, Probst VS, Decramer M, Gosselink R. Characteristics of physical activities in daily life in chronic obstructive pulmonary disease. Am J Respir Crit Care Med. 2005;171(9): 972-977.

17. Troosters T, Sciurba F, Battaglia S, et al. Physical inactivity in patients with COPD, a controlled multi-center pilot-study. Respir Med. 2010; 104(7):1005-1011.

18. Vorrink SN, Kort HS, Troosters T, Lammers JW. Level of daily physical activity in individuals with COPD compared with healthy controls. Respir Res. 2011;12:33.

19. Hartman JE, Boezen HM, Zuidema MJ, de Greef MH, Ten Hacken NH. Physical activity recommendations in patients with chronic obstructive pulmonary disease. Respiration. 2014;88(2):92-100.

20. Lee YJ, Hung WL. The relationship between exercise participation and well-being of the retired elderly. Aging Ment Health. 2011;15(7): 873-881.

21. Sparling PB, Howard BJ, Dunstan DW, Owen N. Recommendations for physical activity in older adults. BMJ. 2015;350:h100.

22. Celli BR, Decramer M, Wedzicha JA, et al. An Official American Thoracic Society/European Respiratory Society Statement: Research questions in chronic obstructive pulmonary disease. Am J Respir Crit Care Med. 2015;191(7):e4-e27.

23. Sundhedsstyrelsen. National klinisk retningslinje for rehabilitering af patienter med KOL; 2014. Available from: https://www.sst.dk/da/ udgivelser/2018/nkr-rehabilitering-af-patienter-med-kol. Accessed October 4, 2018. Danish

24. Miller MR, Hankinson J, Brusasco V, et al. Standardisation of spirometry. Eur Respir J. 2005;26(2):319-338.

25. Demeyer H, Burtin C, van Remoortel H, et al. Standardizing the analysis of physical activity in patients with COPD following a pulmonary rehabilitation program. Chest. 2014;146(2):318-327.

26. Gupta N, Pinto LM, Morogan A, Bourbeau J. The COPD assessment test: a systematic review. Eur Respir J. 2014;44(4):873-884.

27. Thyregod M, Bodtger U. Coherence between self-reported and objectively measured physical activity in patients with chronic obstructive lung disease: a systematic review. Int J Chron Obstruct Pulmon Dis. 2016; 11:2931-2938.

28. Kao CC, Hsu JW, Bandi V, Hanania NA, Kheradmand F, Jahoor F. Resting energy expenditure and protein turnover are increased in patients with severe chronic obstructive pulmonary disease. Metabolism. 2011; 60(10):1449-1455

29. Barreiro E, Gea J. Molecular and biological pathways of skeletal muscle dysfunction in chronic obstructive pulmonary disease. Chron Respir Dis. 2016;13(3):297-311.

30. Demeyer H, Burtin C, Hornikx M, et al. The Minimal Important Difference in Physical Activity in Patients with COPD. PLoS One. 2016; 11(4): $\mathrm{e} 0154587$. 
31. Saunders T, Campbell N, Jason T, et al. Objectively Measured Steps/ Day in Patients With Chronic Obstructive Pulmonary Disease: A Systematic Review and Meta-Analysis. J Phys Act Health. 2016;13(11): 1275-1283.

32. Sewell L, Singh SJ, Williams JE, Collier R, Morgan MD. How long should outpatient pulmonary rehabilitation be? A randomised controlled trial of 4 weeks versus 7 weeks. Thorax. 2006;61(9):767-771.

33. Coronado M, Janssens JP, de Muralt B, Terrier P, Schutz Y, Fitting JW. Walking activity measured by accelerometry during respiratory rehabilitation. J Cardiopulm Rehabil. 2003;23(5):357-364.

34. Dallas MI, McCusker C, Haggerty MC, Rochester CL, Zuwallack R. Northeast Pulmonary Rehabilitation C. Using pedometers to monitor walking activity in outcome assessment for pulmonary rehabilitation. Chron Respir Dis. 2009;6:217-224.

35. Pitta F, Troosters T, Probst VS, Langer D, Decramer M, Gosselink R. Are patients with COPD more active after pulmonary rehabilitation? Chest. 2008;134(2):273-280.

36. Egan C, Deering BM, Blake C, et al. Short term and long term effects of pulmonary rehabilitation on physical activity in COPD. Respir Med. 2012;106(12):1671-1679.

37. Mccarthy B, Casey D, Devane D, Murphy K, Murphy E, Lacasse Y. Pulmonary rehabilitation for chronic obstructive pulmonary disease. Cochrane Database Syst Rev. 2015;2:CD003793.

38. Garvey C, Bayles MP, Hamm LF, et al. Pulmonary Rehabilitation Exercise Prescription in Chronic Obstructive Pulmonary Disease: Review of Selected Guidelines: AN OFFICIAL STATEMENT FROM THE AMERICAN ASSOCIATION OF CARDIOVASCULAR AND PULMONARY REHABILITATION. J Cardiopulm Rehabil Prev. 2016;36(2):75-83.

39. Gore S, Blackwood J, Guyette M, Alsalaheen B. Validity and Reliability of Accelerometers in Patients With COPD. J Cardiopulm Rehabil Prev. 2018;38(3):147-158.
40. Pitta F, Troosters T, Probst VS, Spruit MA, Decramer M, Gosselink R. Quantifying physical activity in daily life with questionnaires and motion sensors in COPD. Eur Respir J. 2006;27(5):1040-1055.

41. Pedersen ES, Danquah IH, Petersen CB, Tolstrup JS. Intra-individual variability in day-to-day and month-to-month measurements of physical activity and sedentary behaviour at work and in leisure-time among Danish adults. BMC Public Health. 2016;16(1):1222.

42. Voigt L, Baumann S, Ullrich A, Weymar F, John U, Ulbricht S. The effect of mere measurement from a cardiovascular examination program on physical activity and sedentary time in an adult population. BMC Sports Sci Med Rehabil. 2018;10(1):1.

43. No authors listed. American College of Sports Medicine Position Stand. The recommended quantity and quality of exercise for developing and maintaining cardiorespiratory and muscular fitness, and flexibility in healthy adults. Med Sci Sports Exerc. 1998;30(6):975-991.

44. Pitta F, Troosters T, Spruit MA, Decramer M, Gosselink R. Activity monitoring for assessment of physical activities in daily life in patients with chronic obstructive pulmonary disease. Arch Phys Med Rehabil. 2005; 86(10):1979-1985.

45. Steele BG, Holt L, Belza B, Ferris S, Lakshminaryan S, Buchner DM. Quantitating physical activity in COPD using a triaxial accelerometer. Chest. 2000;117(5):1359-1367.

46. Brown JP, Martinez CH. Chronic obstructive pulmonary disease comorbidities. Curr Opin Pulm Med. 2016;22(2):113-118.

47. Hornikx M, Van Remoortel H, Demeyer H, et al. The influence of comorbidities on outcomes of pulmonary rehabilitation programs in patients with COPD: a systematic review. Biomed Res Int. 2013:146148.

48. Mesquita R, Vanfleteren LE, Franssen FM, et al. Objectively identified comorbidities in COPD: impact on pulmonary rehabilitation outcomes. Eur Respir J. 2015;46(2):545-548.
International Journal of COPD

\section{Publish your work in this journal}

The International Journal of COPD is an international, peer-reviewed journal of therapeutics and pharmacology focusing on concise rapid reporting of clinical studies and reviews in COPD. Special focus is given to the pathophysiological processes underlying the disease, intervention programs, patient focused education, and self management protocols.

\section{Dovepress}

This journal is indexed on PubMed Central, MedLine and CAS. The manuscript management system is completely online and includes a very quick and fair peer-review system, which is all easy to use. Visit http://www.dovepress.com/testimonials.php to read real quotes from published authors. 